\title{
Study of Third Order Optical Nonlinearity in Disperse Orange-25 Dye-doped Polymer Films using CW Laser
}

\author{
Shubrajyotsna Aithal ${ }^{1}$, P. S. Aithal ${ }^{2}$, \& G. K. Bhat ${ }^{3}$ \\ ${ }^{1}$ Research Scholar, Dept. of Chemistry, Rayalaseema University, Kurnool -518007, \\ Andhra Pradesh, India \\ ${ }^{2}$ Srinivas Institute of Management Studies, Pandeshwar, Mangalore - 575001, India \\ ${ }^{1,3}$ Dept. of Chemistry, Srinivas Institute of Technology, Valachil, Mangalore, 574143, India \\ E-mail: psaithal@gmail.com
}

Type of the Paper: Research Paper.

Type of Review: Peer Reviewed.

Indexed In: OpenAIRE.

DOI: http://dx.doi.org/10.5281/zenodo.818692.

Google Scholar Citation: IJAEML

\section{How to Cite this Paper:}

Aithal, Shubrajyotsna., Aithal, P. S., \& Bhat, G. K. (2017). Study of Third Optical Nonlinearity in Disperse Orange-25 Dye-doped Polymer Films using CW Laser. International Journal of Applied Engineering and Management Letters (IJAEML), 1(1), 18-35.

DOI: http://dx.doi.org/10.5281/zenodo.818692.

International Journal of Applied Engineering and Management Letters (IJAEML)

A Refereed International Journal of Srinivas University, India.

(c) With Authors.

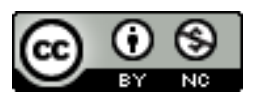

This work is licensed under a Creative Commons Attribution-Non Commercial 4.0 International License subject to proper citation to the publication source of the work.

Disclaimer: The scholarly papers as reviewed and published by the Srinivas Publications (S.P.), India are the views and opinions of their respective authors and are not the views or opinions of the S.P. The S.P. disclaims of any harm or loss caused due to the published content to any party. 


\title{
Study of Third Order Optical Nonlinearity in Disperse Orange-25 Dye-doped Polymer Films using CW Laser
}

\author{
Shubrajyotsna Aithal ${ }^{1}$, P. S. Aithal ${ }^{2}$, \& G. K. Bhat ${ }^{3}$ \\ ${ }^{1}$ Research Scholar, Dept. of Chemistry, Rayalaseema University, Kurnool -518007, \\ Andhra Pradesh, India \\ ${ }^{2}$ Srinivas Institute of Management Studies, Pandeshwar, Mangalore - 575001, India \\ 1,3 Dept. of Chemistry, Srinivas Institute of Technology, Valachil, Mangalore, 574143, India \\ E-mail: psaithal@gmail.com
}

\begin{abstract}
The organic materials with the ability of self-focussing/defocusing through their light intensity-dependent refractive index and phase shift properties are potential materials in alloptical photonic devices have become interesting topic of continuous research. Several organic materials including dye-doped polymer films are attracting many researchers due to their advantages in terms of enhanced efficiency, and acceptable mechanical properties to fabricate useful devices. In this paper, we have reported the nonlinear optical properties like nonlinear absorption and nonlinear refraction of an organic dye Disperse Orange-25 (DO-25) doped in Polymethyl methacrylate-methacrylic acid (PMMA-MA) polymer matrix using open aperture and closed aperture Z-scan experimental methods by means of low power continuous wave (CW) laser beam. The optical limiting properties of these films are also studied using Type 1 and Type 2 configurations at different input powers using continuous wave (CW) laser beams of $532 \mathrm{~nm}$ wavelength. The nonlinear refractive index $n_{2}$, nonlinear absorption coefficient $\beta$, changes in refractive index with input intensity, and the magnitude of third-order optical nonlinearity of the dye-doped film are experimentally determined. The saturated output power for type 1 and type 2 optical limiting are determined. The input limiting threshold and saturated output power level for both type 1 and type 2 optical limiting configurations are recorded. DO-25 dye-doped in PMMA-MA polymer film has shown saturation absorption at lower input irradiance and reverse saturation absorption at higher input irradiance and hence found to be a potential candidate for the third harmonic property based photonic devices.
\end{abstract}

Keywords: Organic Nonlinear material, Dye-doped polymer films, Optical limiting, Open and closed aperture Z scan. DO-25 doped PMMA-MA films.

\section{INTRODUCTION :}

The organic materials with ability of self-focussing/defocusing through their light intensity-dependent refractive index and phase shift properties are potential materials in all-optical photonic devices have become interesting topic of continuous research. Several organic materials including dye-doped polymer films are attracting many researchers due to their advantages in terms of enhanced efficiency, and acceptable mechanical properties to fabricate useful devices [1-4]. Many research results have been published on different organic nonlinear optical materials which include molecular single crystals, organic molecules in solution forms, and organic dyes and organometallics doped in different solid matrices. The mechanisms like Reverse Saturation Absorption (RSA), Two-Photon Absorption (TPA), nonlinear refraction, nonlinear scattering, and thermal nonlinearity are used in organic materials for optical power limiting. Similarly, the optical phase conjugation through four-wave mixing is demonstrated in some of the gases, organic and inorganic crystals, and films using both 
pulsed and continuous wave (CW) lasers. Polymers, glasses and other types of solid matrices doped by nonlinear organic dyes are considered as promising materials for optical phase conjugation (OPC) due to their enhanced third-order nonlinear susceptibilities [5-10]. In this paper, we have reported the nonlinear optical properties like nonlinear absorption and nonlinear refraction of an organic dye Disperse Orange-25 (DO-25) doped in Polymethyl methacrylate-methacrylic acid (PMMA-MA) polymer matrix using open aperture and closed aperture Z-scan experimental methods by means of low power continuous wave (CW) laser beam. The optical limiting properties of these films are also studied using Type 1 and Type 2 configurations at different input powers using continuous wave (CW) laser beams of $532 \mathrm{~nm}$ wavelength. The nonlinear refractive index $n_{2}$, nonlinear absorption coefficient $\beta$, changes in refractive index with input intensity, and the magnitude of third-order optical nonlinearity of the dye-doped film are experimentally determined. In this paper, we have reported the nonlinear optical properties like nonlinear absorption and nonlinear refraction of an organic dye Disperse Orange-25 (DO-25) doped in Polymethyl methacrylate-methacrylic acid (PMMA-MA) polymer matrix using open aperture and closed aperture Z-scan experimental methods by means of low power continuous wave (CW) laser beam. The optical limiting properties of these films are also studied using Type 1 and Type 2 configurations at different input powers using continuous wave (CW) laser beams of $532 \mathrm{~nm}$ wavelength. The nonlinear refractive index $n_{2}$, nonlinear absorption coefficient $\beta$, changes in refractive index with input intensity, and the magnitude of third-order optical nonlinearity of the dye-doped film are experimentally determined.

\section{MOLECULAR STRUCTURE AND LINEAR OPTICAL PROPERTIES OF DO-25 :}

[3-[N-ethyl-4-(4-nitrophenvlazo)phynvl-aminolpropionitrile]

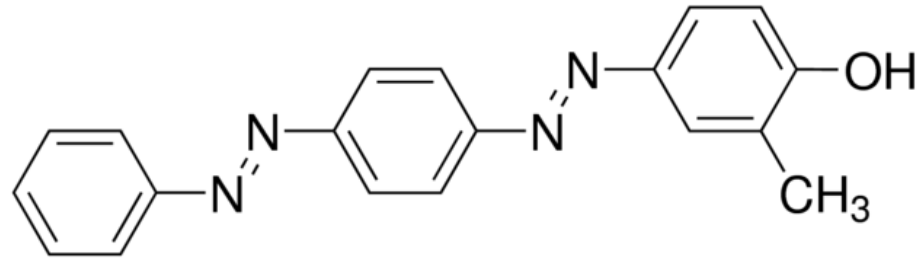

Figure 1: Molecular structure of Disperse Orange - 25 .

Commercially available Disperse orange- 25 is purchased by Aldrich Chemical Company, USA. and further filtered and recrystallized using spectrograde ethanol. The research grade chloroform is used as the solvent. The thin films of DO-25 doped in polymer matrix by dissolving both DO-25 and PMMA-MA in specified quantity in chloroform. The solution mixtures are poured between two micro glass slides in a clean laboratory environment and thin films of both the dye samples of specified thickness are prepared using hot press technique [11]. Thin films of $10 \mu \mathrm{m}$ thickness of both DO-25 dye-doped polymer films are prepared between two glass slides separately. The thickness of the films is determined by gravimetric weighing method. The film thickness is determined to be $10 \mu \mathrm{m}$ for the solution molarity of $1 \mathrm{mM}, 2 \mathrm{mM}, \& 5 \mathrm{mM}$. This is consequently verified by the cross-sectional studies of the film using Scanning Electron Microscope by mounting the film vertically to measure the thickness directly [12].

The linear absorption coefficient $\alpha_{0}$ is determined for two wavelengths $1.06 \mu \mathrm{m}$ and $532 \mathrm{~nm}$ by using formula $\alpha_{0}=-\frac{1}{t} \ln \left[\frac{1}{T}\right]$

where $(\mathrm{t})$ is the thickness of sample and $\mathrm{T}$ is the transmittance.

Table 1: Linear absorption coefficient and refractive index versus wavelength of DO-25.

\begin{tabular}{|l|l|l|l|l|}
\hline Wavelength (nm) & Thickness $(\boldsymbol{\mu m})$ & Transmittance & $\boldsymbol{\alpha}_{\mathbf{0}}(\boldsymbol{\mu m})^{-\mathbf{1}}$ & $\mathbf{n}_{\mathbf{0}}$ \\
\hline 532 & 10 & 0.6 & -0.0510786 & 2.999 \\
\hline 633 & 10 & 0.9 & -0.010536 & 1.8070 \\
\hline 1064 & 10 & 0.98 & -0.0020195 & 1.22345 \\
\hline
\end{tabular}

The refractive index $\mathrm{n}_{0}$ can be found from transmittance spectrum of the film according to the 
following equation

$n_{0}=\frac{1}{\mathrm{~T}}+\left[\left(\frac{1}{\mathrm{~T}^{2}}-1\right)\right]^{1 / 2}$

The linear absorption coefficient and refractive index are shown in Table 1.

The absorption spectra of the thin DO-25 dye-doped films is shown in figure 3 infer that transmission through these films is relatively low at below band gap region, indicating a high concentration of defects, free carriers. The transmittance increases abruptly in the short wavelengths which are due to the band edge absorption. A sudden increase at a particular wavelength indicates the presence of optical band gap in these samples. The incoming photons get sufficient energy to excite electrons from the valence band to the conduction band, which results in strong absorption in dye samples. The optical absorption edge is determined by the optical absorption, a simple and common method used that provides an explanation for the features concerning the band structure of the films [13-15].

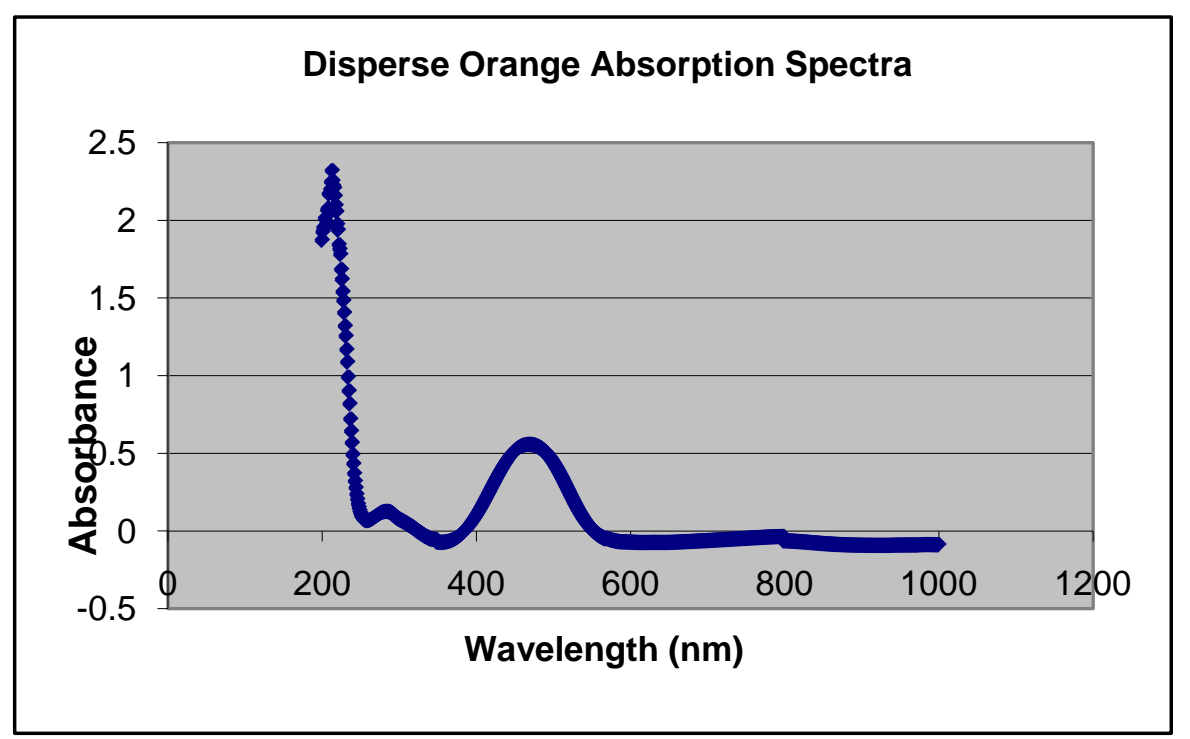

Figure 2: Absorption spectra of the thin DO-25 dye-doped films

Table 2: Physical parameters and Linear Absorption properties of DO-25 dye-doped film.

\begin{tabular}{|l|l|l|}
\hline S. No. & Parameter/Property & $\begin{array}{l}\text { DO-25 } \\
\text { in PMMA-MA }\end{array}$ \\
\hline 1 & Linear absorption range (bandwidth) & $100 \mathrm{~nm}$ \\
\hline 2 & Linear absorption peak (nm) & $468 \mathrm{~nm}$ \\
\hline 3 & Linear Transmission Range $(\mathrm{nm})$ & $530-1,600$ \\
\hline 4 & Linear Transmittance $(\mathrm{T})$ at $532 \mathrm{~nm}$ & 0.6 \\
\hline 5 & Linear absorption coefficient $\left(\alpha_{0}\right)$ at $532 \mathrm{~nm}$ & -0.0510786 \\
\hline 6 & Linear Refractive index $\left(\mathrm{n}_{0}\right)$ at $532 \mathrm{~nm}$ & 2.999 \\
\hline 7 & Dye concentrations in prepared films & $1 \mathrm{mM}, 2 \mathrm{mM}, \& 5 \mathrm{mM}$ \\
\hline 8 & Dye concentration in the solution $($ Chloroform) & $0.0001 \mathrm{~mol} / \mathrm{L}$ \\
\hline 9 & Film Thickness & $10 \mu \mathrm{m}$ \\
\hline 10 & Single photon florescence Peak & Not applicable \\
\hline
\end{tabular}

\section{NONLINEAR OPTICAL PROPERTIES OF DO-25 :}

\subsection{Nonlinear Absorption Study (Open Aperture Z-Scan) : :}

The block diagram of the experimental setup used for the open aperture Z-scan study of DO-25 doped in PMMA-MA film is shown in figure 3. The CW diode laser of wavelength $532 \mathrm{~nm}$ (30 mW Green Light Line) is used as the excitation source and the Gaussian beam is focused by means of a $3.5 \mathrm{~cm}$ focal length convex lens (L1), which produced a beam waist $\omega_{0}$ of $15 \mu \mathrm{m}$. The peak intensity of the incident laser beam is calculated as $\mathrm{I}_{0}=3: 5 \mathrm{~kW} / \mathrm{cm}^{2}$ and the diffraction length $\left(Z_{\mathrm{R}}\right)$ is calculated as 2.5 $\mathrm{mm}$. The input power adjusted and noted by means of a convex lens (L3), Photo detector (P.D.1) and 
digital power meter assembly. The DO-25 dye-doped polymer sample is translated across the focal region of lens $\mathrm{L} 1$ along the axial direction that is the direction of the propagation of the laser beam. The transmitted beam is collected by means of a convex lens (L2) and the output intensity is measured using photo detector (P.D.2) fed to the digital power meter. The experimental setup used in the open aperture Z-scan is not sensitive to nonlinear refraction and hence can be used to determine the nonlinear absorption cross section of the materials. Such open aperture Z-scan trace is expected to be symmetric with respect to the focus where $Z=0$, and at the focus, the minimum transmittance (e.g., multi-photon absorption/reverse saturation absorption) or a maximum transmittance (e.g., saturation of absorption) occurs. The nonlinear absorption coefficient $(\beta)$ can be estimated from Z-scan transmittance curve (Eq. 3). The Z- scan experiment is performed for DO-25 dye-doped PMMA-MA polymer films of the dye concentration $1 \mathrm{mM}, 2 \mathrm{mM}$, and $5 \mathrm{mM}$ using $532 \mathrm{~nm}$ laser beam at $10 \mathrm{~mW}, 20$ $\mathrm{mW}$ and $30 \mathrm{~mW}$. The results are depicted in Fig. 4, to Fig. 6 respectively.

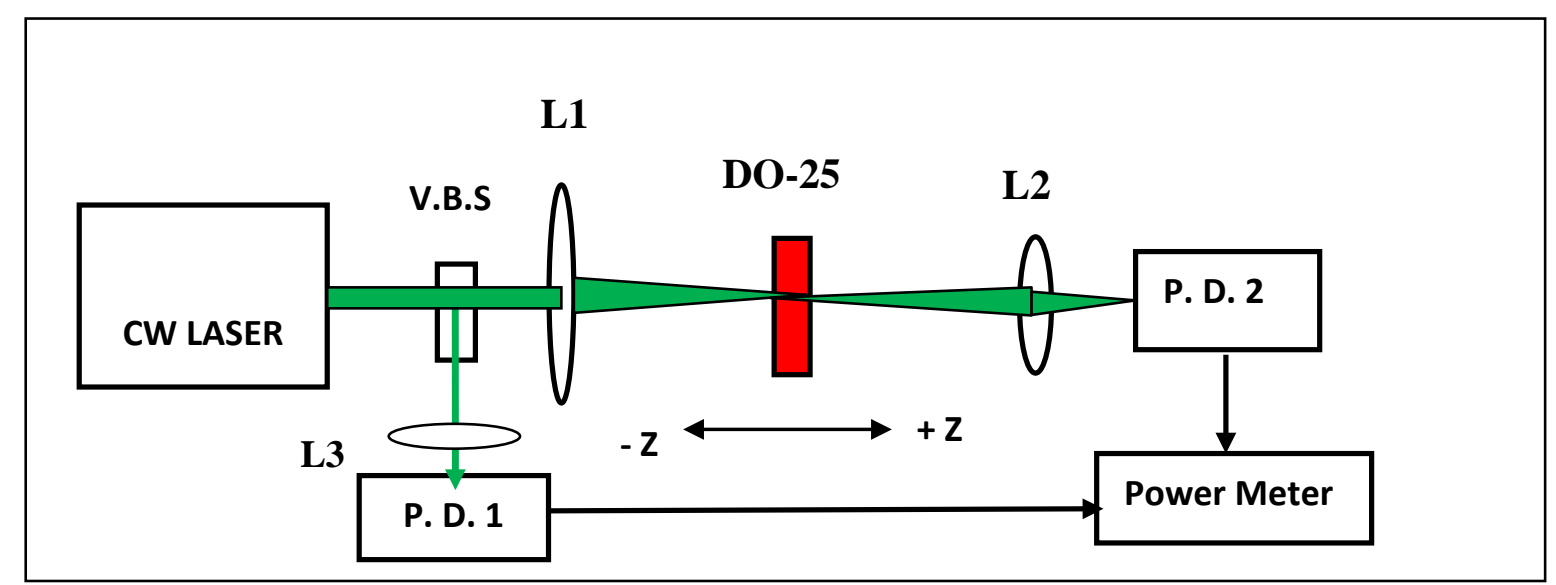

Figure 3: Experimental setup for open aperture Z scan for DO-25 samples.

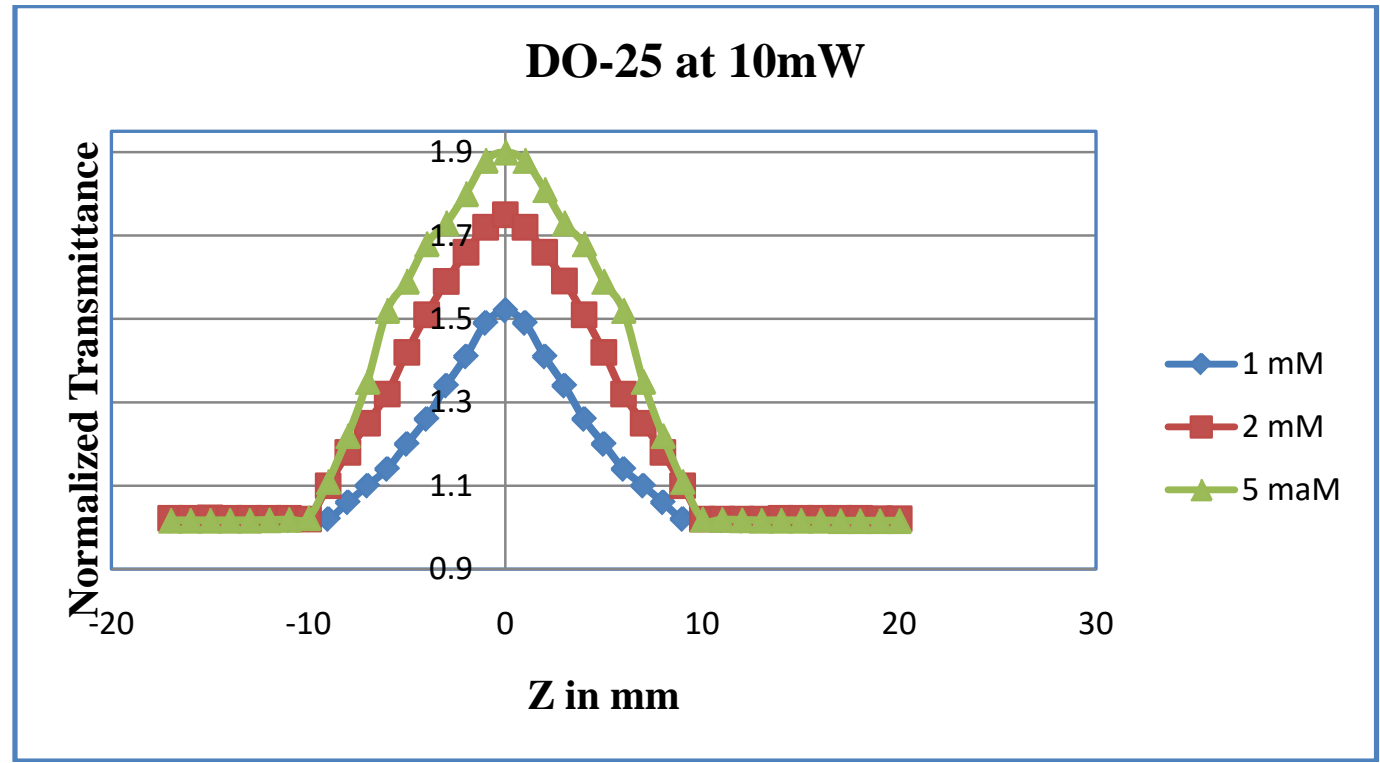

Figure 4: CW Open aperture Z-scan plot of DO-25 at different dye concentrations using $532 \mathrm{~nm}, 10$ $\mathrm{mW}$ laser beams.

In Z-scan open aperture graph, the dye sample DO-25 has shown a decrease in transmittance with an increase in irradiance/input intensity due to reverse saturation absorption [16-17]. It is seen from the Z-scan plot that the DO-25 shows strong saturable absorption at low input intensity of laser beam. 


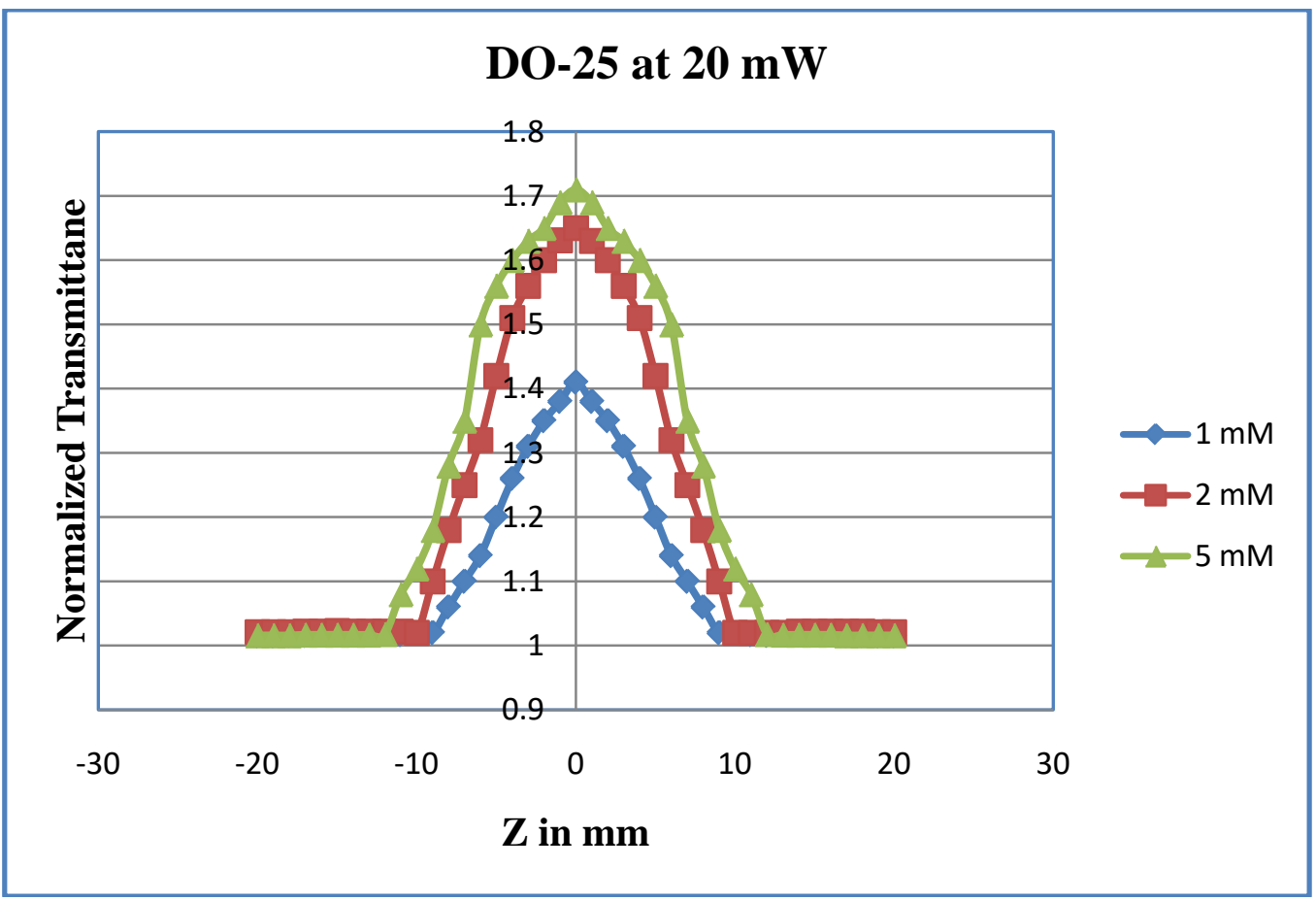

Figure 5: CW Open aperture Z-scan plot of DO-25 at different dye concentrations using 532 nm, 20 $\mathrm{mW}$ laser beams.

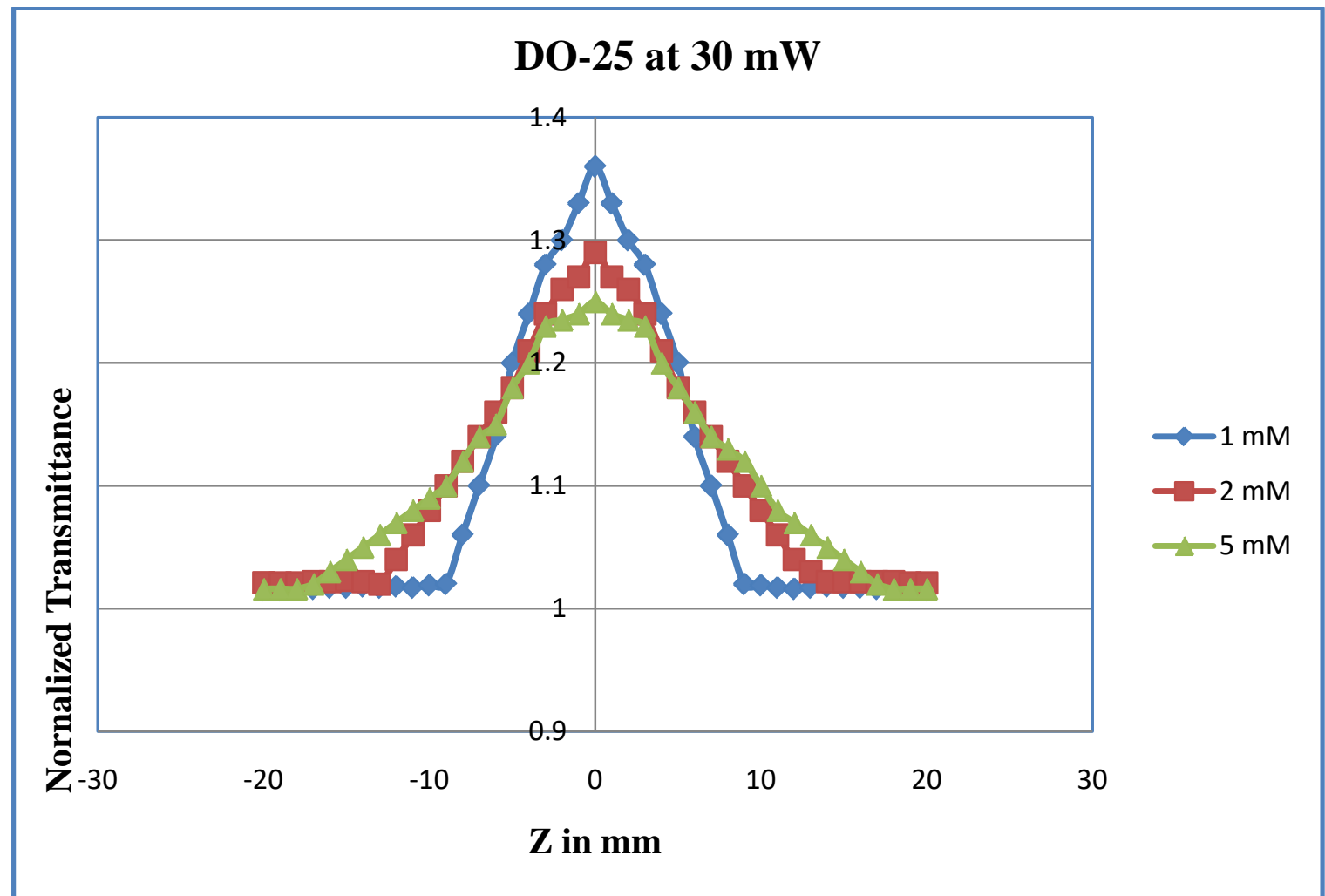

Figure 6 : CW Open aperture Z-scan plot of DO-25 at different dye concentrations using $532 \mathrm{~nm}, 30$ $\mathrm{mW}$ laser beam.

From the open aperture Z-scan, it is observed that due to nonlinear absorption, the transmittance of the DO-25 film is increased initially with an increase in intensity due to saturation of absorption and as input power increases, the saturation absorption (SA) is overtaken by reverse saturation absorption 
(RSA) as seen in figure 6. Such transformation from saturation absorption to reverse saturation absorption can be utilized as a principle for the construction of optical switches as well as optical limiters.

Based on open aperture Z-scan plots of DO-25 for different concentrations and at different input power, it is observed that:

(i) At low input power, saturation absorption (SA) increased with increase in the concentration of dye in the sample.

(ii) At the higher intensity of input light, DO-25 has shown reverse saturation absorption (RSA) so that saturation absorption (SA) of the sample is decreased.

From the graphs (figure 5 and figure 6), reverse saturable absorption (RSA) is seen in the open aperture Z-scan trace for DO-25 dye doped in PMMA-MA film as it shows minimum transmittance with increase in intensity of input laser beam. The nonlinear absorption coefficient $\beta$ can be estimated from the open aperture Z-scan data, where

$\beta=(2 \sqrt{2} \Delta T) /\left(I_{0} L_{\text {eff }}\right)$----- (3)

Here, $\mathrm{I}_{0}$ is the intensity at the focal spot and is given by

$I_{0}=2 P_{\text {peak }} / \pi \omega_{0}^{2}$

The effective length of the sample can be determined from the formula

$L_{e f f}=\left(1-e^{-\alpha_{0} L}\right) / \alpha_{0}$------ (5)

For low input intensity, the transmittance increases with the increase in excitation intensity and has a maximum value at the focus. As input power is increased, the sample has shown a decrease in transmittance which is the signature of reverse saturation absorption according to Sheik-Bahae's theory [18-19]. When reverse saturation absorption occurs, the absorption coefficient $\beta$ is no longer a constant. Instead, it becomes a function of the excitation intensity as in the relation,

$\alpha=\alpha_{0}+\mathrm{I} \beta$------- (6)

here, $\alpha$ is the total absorption coefficient of the material, $\alpha_{0}$ is the linear absorption coefficient of the material, $\beta$ is the nonlinear absorption coefficient of the material, and I is the input intensity of the laser beam.

By considering only third-order nonlinearities in the sample, the total refractive index of the sample (n) becomes:

$\mathrm{n}=\mathrm{n}_{0}+\mathrm{n}_{2} \mathrm{I}$.

where $\Delta \mathrm{n}=\mathrm{n}_{2}$ I is change in refractive index, $\mathrm{n}_{0}$ is the linear refractive index of the sample, $\mathrm{n}_{2}$ is the nonlinear refractive index for third-order nonlinear sample, and $\mathrm{I}$ is the input intensity of the laser beam.

Reverse saturable absorption is seen in the open aperture Z-scan trace for DO-25 dye in PMMA-MA matrix as it shows minimum transmittance. The nonlinear absorption coefficient $\beta$ can be estimated from the open aperture Z-scan data using eq. (3). The transmittance increases with the increasing input intensity and has a maximum value at the focus where $\mathrm{Z}=0$, which is the sign of saturation absorption according to Sheik-Bahae's theory. In eq. (3), $\Delta \mathrm{T}$ is maximum transmittance at the focus (at $\mathrm{Z}=0$ ). When saturation absorption occurs, the absorption coefficient $\alpha$ will not become a constant. Instead, it will become a function of the excitation intensity as in the relation, $\alpha=\alpha_{0}+\mathrm{I} \beta$ where $\alpha_{0}$ is the linear absorption coefficient and $\beta$ is its nonlinear counterpart. The experimental values of nonlinear absorption coefficient $\beta$ at different dye concentrations for DO-25 dye-doped PMMA-MA films at $20 \mathrm{~mW}$ input power are listed in table 3.

Table 3 : Nonlinear absorption coefficient values for DO-25 dye-doped PMMA-MA film.

\begin{tabular}{|l|l|l|l|l|}
\hline $\begin{array}{l}\text { Wavelength } \\
(\mathbf{n m})\end{array}$ & Concentration & $\mathbf{\Delta T}$ & $\mathbf{I}_{\mathbf{0}}\left(\mathbf{K W} / \mathbf{c m}^{\mathbf{2}}\right)$ & $\begin{array}{l}\boldsymbol{\beta} \\
(\mathbf{c m} / \mathbf{W}) \times \mathbf{1 0}^{-\mathbf{3}}\end{array}$ \\
\hline 532 & $1 \mathrm{mM}$ & 0.14 & 3.5 & -0.74 \\
\hline 532 & $2 \mathrm{mM}$ & 0.11 & 3.5 & -0.88 \\
\hline 532 & $5 \mathrm{mM}$ & 0.092 & 3.5 & -1.13 \\
\hline
\end{tabular}

3.2 Nonlinear Refraction Study (Closed Aperture Z-Scan) :

The experimental set-up used for the closed aperture $Z$-scan measurement is same as the setup used for open aperture Z-scan except for the output beam from the dye sample is collected through an 
aperture of a fixed hole size instead of collecting entire output beam through collecting lens L2. The diode laser of wavelength $532 \mathrm{~nm}$ (BeamQ $30 \mathrm{~mW}$ Green Light Line) is used as the excitation source and the Gaussian beam is focused by means of a $3.5 \mathrm{~cm}$ focal length convex lens (L1), which produced a beam waist $\omega_{0}$ of $15 \mu \mathrm{m}$. The peak intensity of the incident laser beam is calculated as $\mathrm{I}_{0}=$ $3: 5 \mathrm{~kW} / \mathrm{cm}^{2}$ and the diffraction length $\left(Z_{\mathrm{R}}\right)$ is calculated as $2.5 \mathrm{~mm}$. The schematic of the experimental setup used is shown in figure 7. The dye sample is translated across the axial focal region along the direction of the propagation laser beam. The transmitted laser beam through an aperture placed in the far field is measured using photo detector fed to the digital power meter. The closed aperture Z-scan plot between $\mathrm{Z}$ in $\mathrm{mm}$ and normalized transmittance for different dye concentrations is shown in figure 8 .

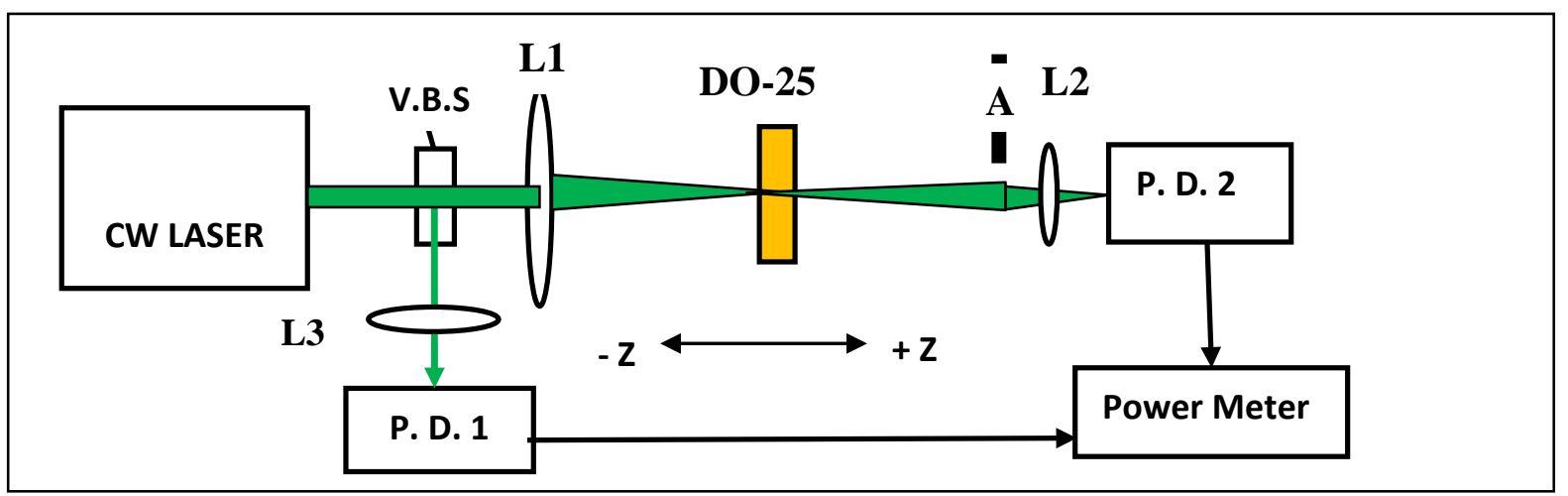

Figure 7: Experimental setup for closed aperture Z scan for DO-25 sample film.

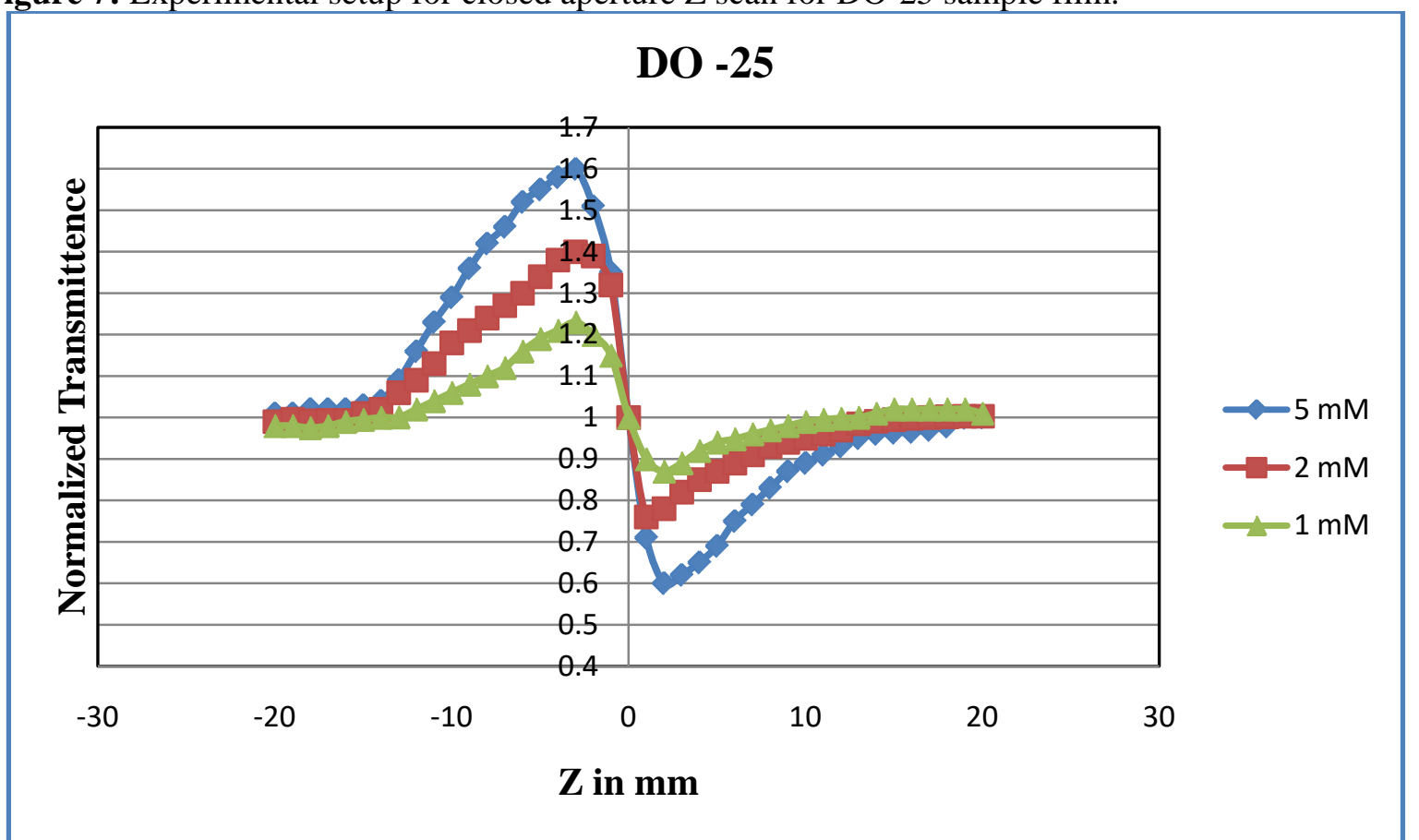

Figure 8: Closed-aperture CW Z-Scan with both refractive and absorptive nonlinearity at $532 \mathrm{~nm}$ for DO-25 (20 mW).

The normalized transmittance curve obtained from the closed aperture Z-scan data contains a positive peak followed by a negative valley, which indicates that the sign of the refraction nonlinearity is negative, i.e. the dye sample shows self-defocusing nonlinearity. This self-defocusing effect is mainly due to the local changes in the refractive index with variation in temperature. It can be argued that the defocusing effect for the dye in polymer film shown in figure 8 is attributed to a thermal nonlinearity resulting from the absorption of radiation at $532 \mathrm{~nm}$. From the normalized nonlinear refraction graph, the measurable quantity $\Delta T_{\mathrm{p}-\mathrm{v}}$ can be defined as the difference between the normalized peak and 
valley transmittances. Since the closed aperture transmittance is affected by the nonlinear refraction and nonlinear absorption, to determine nonlinear refractive coefficient, it is necessary to separate the nonlinear refraction effect from nonlinear absorption effect. As per Sheik-Bahae [20-21], an effective method to obtain purely nonlinear refractive index $\mathrm{n}_{2}$ is to divide the closed aperture transmittance data by the corresponding open aperture scan data. The $Z$-scan curve for pure nonlinear refraction for $5 \mathrm{mM}$ concentration DO-25 dye doped sample is shown in figure 9 at the input laser beam intensity of $20 \mathrm{~mW}$. Experimentally determined nonlinear refractive index $n_{2}$ and nonlinear absorption coefficient $\beta$ can be used to calculate the absolute value of the third-order nonlinear optical susceptibility [22-23]. In order to know the contribution from pure PMMA-MA polymer film to the observed nonlinear response, the Z-scan is performed on pure film without doping DO-25 dye. Neither nonlinear absorption nor nonlinear refraction is observed. The nonlinear refractive index $\mathrm{n}_{2}$ can be calculated using the Eq. (8). The experimental values of nonlinear phase shift and nonlinear refractive index for DO-25 dye-doped PMMA-MA film are listed in Table 4.

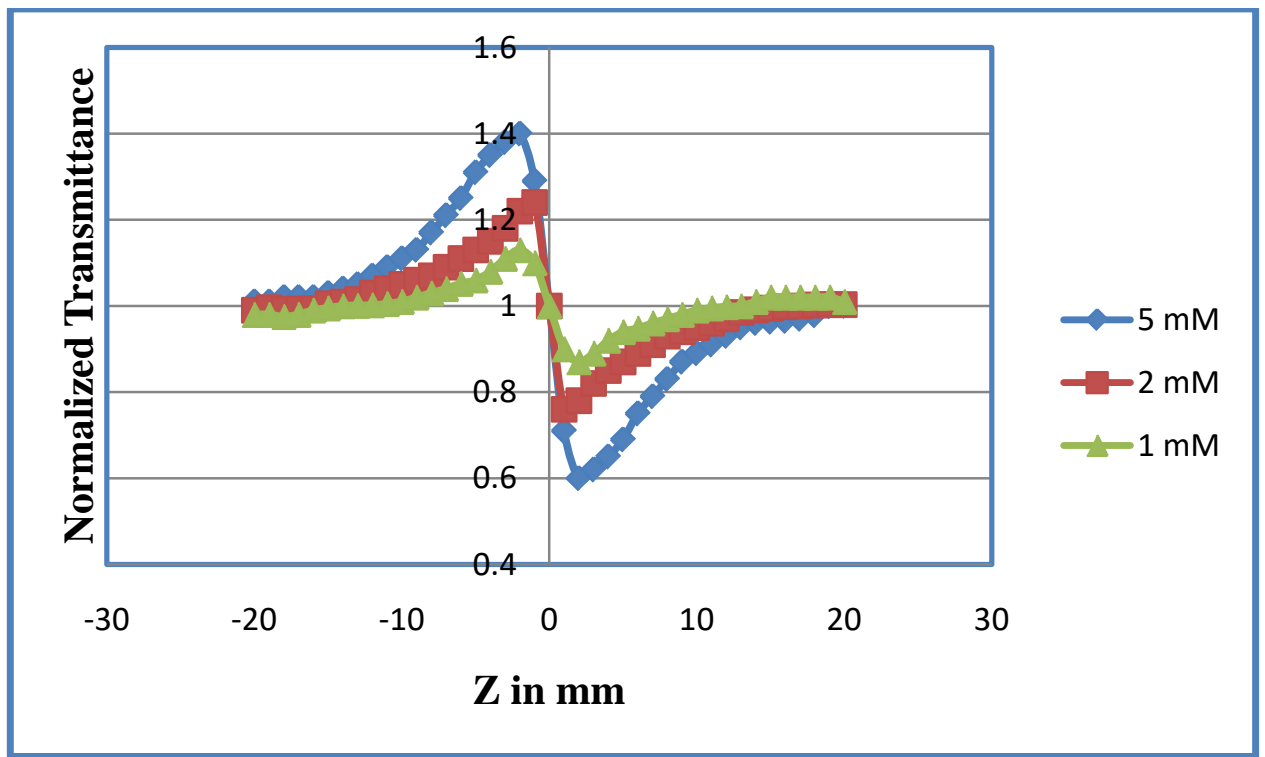

Figure 9: Closed-aperture CW Z-Scan with pure refractive nonlinearity at $532 \mathrm{~nm}$ for DO-25 (20 mW).

The nonlinear refractive index $\mathrm{n}_{2}$ can be calculated using the formula $\mathrm{n}_{2}=\frac{\Delta \emptyset \lambda}{2 \pi I_{0} L_{e f f}}$

and $|\Delta \emptyset|=\Delta \mathrm{T}_{(\mathrm{p}-\mathrm{v})} /\left[0.406(1-\mathrm{S})^{0.25}\right]$

where $\Delta \mathrm{T}_{\mathrm{p}-\mathrm{v}}$ is the peak-valley transmittance difference from the closed aperture plot, $\left|\Delta \emptyset_{0}\right|$ is the on axis nonlinear phase-shift and $\mathrm{S}$ is the aperture linear transmittance given by $\mathrm{S}=\left[1-\exp \left(-2 r_{a}^{2} / w_{a}^{2}\right)\right]$ where $r_{a}$ is the aperture radius and $w_{a}$ is the beam radius at the aperture. $S=1$ for open aperture configuration and $S$ is adjusted to 0.5 for our closed aperture configurations. In Eq. (8), $I_{0}$ is the intensity at the focal spot as per Eq. (4) and $\mathrm{L}_{\text {eff }}$ is the effective length of the sample and is given by Eq. (5).

The change in refractive index $\Delta \mathrm{n}$ can be calculated using the formula, $\Delta \mathrm{n}=\mathrm{n}_{2} \mathrm{I}_{0}$

Table 4 : Nonlinear refractive index and nonlinear phase shift for DO-25 film.

\begin{tabular}{|l|l|l|l|l|l|}
\hline $\begin{array}{l}\text { Wavelength } \\
(\mathbf{n m})\end{array}$ & Concentration & $\mathbf{\Delta} \mathbf{T}_{\mathbf{p}-\mathbf{v}}$ & $\mathbf{I}_{\mathbf{0}} \mathbf{K W} / \mathbf{c m}^{2}$ & $\Delta \emptyset_{\text {rad }}$ & $\begin{array}{l}\mathbf{n}_{\mathbf{2}}\left(\mathbf{c m}^{2} / \mathbf{W}\right) \\
\times \mathbf{1 0}^{-8}\end{array}$ \\
\hline 532 & $1 \mathrm{mM}$ & 0.38 & 3.5 & 1.113 & -3.25 \\
\hline 532 & $2 \mathrm{mM}$ & 0.65 & 3.5 & 1.904 & -5.57 \\
\hline 532 & $5 \mathrm{mM}$ & 1.0 & 3.5 & 2.929 & -8.36 \\
\hline
\end{tabular}

3.3 Third-order Nonlinear Optical Susceptibility $\left|\chi^{(3)}\right|$ : 
The Z- scan plot of DO-25 dye in PMMA-MA polymer film, show a pre-focal transmittance maximum (peak) followed by a post-focal transmittance minimum (valley). This indicates that DO-25 has a negative non-linearity due to self-defocussing. Self-defocussing is due to variation in refractive index with the nonlinear absorption and thermal lensing effect. The nonlinear refractive index $n_{2}$ can be calculated using the Eq. (8) and change in refractive index, $\Delta \mathrm{n}$ can be calculated using Eq. (10). Experimentally determined nonlinear refractive index $\mathrm{n}_{2}$ can be used to find the real part of the thirdorder nonlinear optical susceptibility $\left[\chi^{3}\right]$ according to the following relation [24-25].

$\operatorname{Re} \chi^{(3)}=\left|\chi^{3}\right|=\frac{10^{-4} \epsilon_{0}\left(n_{0}^{2}\right) c^{2} n_{2}}{\pi}\left(\mathrm{cm}^{2} / \mathrm{W}\right)$

Experimentally determined nonlinear absorption coefficient $\beta$ can be used to find the imaginary part of the third-order nonlinear optical susceptibility $\left[\chi^{3}\right]$ according to the following relation

$\operatorname{Im} \chi^{(3)}=\frac{10^{-2} \epsilon_{0}\left(n_{0}^{2}\right) c^{2} \lambda}{4 \pi^{2}} \quad\left(\mathrm{~cm}^{2} / \mathrm{W}\right)$

The absolute value of the third-order nonlinear optical susceptibility is given by the relation

$\left|\chi^{3}\right|=\left[\left(\operatorname{Re} \chi^{(3)}\right)^{2}+\left(\operatorname{Im} \chi^{(3)}\right)^{2}\right]^{1 / 2}$

Where $\epsilon_{0}$ is the vaccum permitivity and $C$ is the light velocity in vacuum.

The nonlinear parameters, such as nonlinear refractive index $\left(n_{2}\right)$, change in refractive index $(\Delta n)$, the nonlinear absorption coefficient $(\alpha)$ and nonlinear susceptibility $\left(\chi^{(3)}\right)$ are calculated and listed in Table 5.

Table 5: Third harmonic susceptibility of DO-25 film.

\begin{tabular}{|c|c|c|c|c|}
\hline $\begin{array}{l}\text { Wavelength } \\
(\mathrm{nm})\end{array}$ & Concentration & $\begin{array}{l}\mathrm{n}_{2}\left(\mathrm{~cm}^{2} / \mathrm{W}\right) \\
\times 10^{-8}\end{array}$ & $\begin{array}{l}\Delta \mathbf{n} \\
\left(\times 10^{-4}\right)\end{array}$ & $\begin{array}{l}{\left[\chi^{3}\right] \text { (esu) }} \\
\times 10^{-6}\end{array}$ \\
\hline \multirow{3}{*}{532} & $1 \mathrm{mM}$ & -3.25 & -1.138 & 5.69 \\
\hline & $2 \mathrm{mM}$ & -5.57 & -1.950 & 7.45 \\
\hline & $5 \mathrm{mM}$ & -8.36 & -2.926 & 9.73 \\
\hline
\end{tabular}

\section{CW OPTICAL LIMITING STUDY :}

The optical limiting effect of the DO-25 dye-doped polymer film is studied by means of a $30 \mathrm{~mW}$ CW semiconductor laser beam at $532 \mathrm{~nm}$ (30 mW Green Light Laser). Two experimental set-ups are used for the demonstration of optical limiting. In the first experimental setup, the dye sample is placed in the focus of the focusing lens L1 of Z-scan setup. The emergent beam from the dye sample is collected to a photo detector by means of a collecting lens L2 to measure the output power. By fixing the sample position at the focus, the input power is varied and output power is noted. Such experimental setup is named as Optical limiting without an aperture or Type $\mathbf{1}$ optical limiting. This type of optical limiting study will take care of nonlinear absorption property of the dye sample. In the second experimental setup, an aperture of fixed hole size is used between the dye sample and the collecting lens \& photo detector. The DO-25 dye film is kept at a point along the beam axis where the transmitted light intensity shows a valley in closed aperture Z-scan curve [26-28]. The input intensity of laser beam is varied and the corresponding output intensity is noted by a photo detector power meter assembly. Such experimental setup is named as Optical limiting with an aperture or Type 2 optical limiting. This type of optical limiting study will take care of nonlinear refraction property of the dye sample.

\section{Case (1): Optical Limiting without Aperture (Type 1) :}

The pure nonlinear absorption property of the dye sample is measured using this method of optical limiting without aperture at the output side (Type- 1 optical limiting). The entire light beam transmitted through the sample is focused by a collecting lens to the photo detector-power meter assembly. The optical limiting effects of the DO-25 dye-doped PMMA-MA films are studied by using a CW laser source (30 $\mathrm{mW}$ Green Light Laser). The experimental set-up for the demonstration of type-1 optical limiting is shown in figure 10. The dye sample is kept fixed at the focal point of a convex lens L1 of open aperture Z-scan setup. A variable beam splitter (VBS) is utilized to change the input power. By means of a convex lens, the output light beam is made to fall on the photo detector (PD). The input light intensity is increased systematically and the corresponding output intensity is measured by a photo detector. The output power is measured using a power meter. The experiment is 
performed at different input power and the corresponding output power of transmitted beam is noted and a graph is drawn between input power and output power for different dye concentrations and is shown in figure 11.

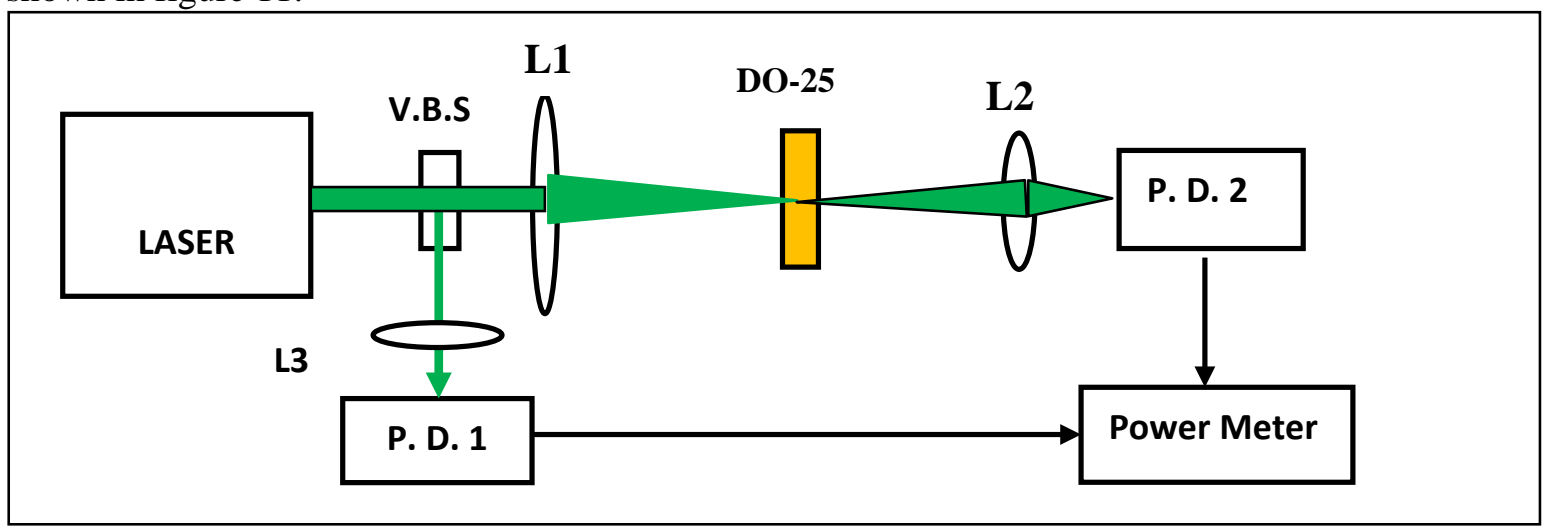

Figure 10 : Experimental setup for Optical limiting (Type 1) due to pure absorptive nonlinearity.

In this case, the intensity of the transmitted output beam from the DO-25 dye-sample is observed to change linearly at lower values of the input intensity but observed to saturate at higher incident intensities due to nonlinear reverse saturation absorption and thermal lensing. Hence, after a certain threshold value of the input intensity, the nonlinear absorption of the DO-25 dye sample becomes dominant, resulting in the limiting of the intensity of output beam. Thus the transmittance recorded by the photo detector remained reasonably constant showing a saturation region in the graph.

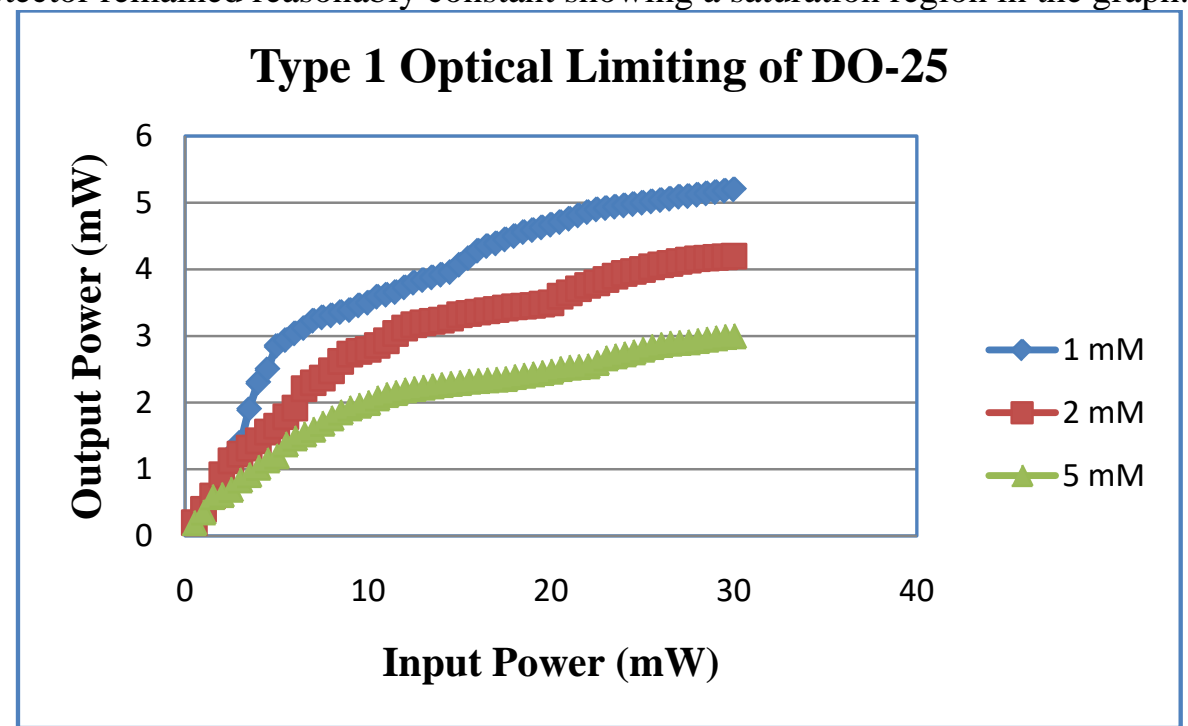

Figure 11: Open aperture (Type 1) Optical limiting behavior of DO-25 dye-doped PMMA-MA film at CW $532 \mathrm{~nm}$.

\section{Case (2) Optical Limiting with Aperture (Type 2) :}

The pure nonlinear refraction property of the dye sample is measured using this method of optical limiting with an aperture at the output side (Type-2 optical limiting). The light beam transmitted through the sample is passed through an aperture A of fixed diameter and then passed through a collecting lens L2 to the photo detector-power meter assembly. The optical limiting effects of the DO25 dye-doped PMMA-MA films are studied by using a CW laser source. The experimental set-up for the demonstration of type-2 optical limiting is shown in figure 12. The dye sample is kept at the position where the transmitted intensity shows a valley in the closed aperture Z-scan curve. The experiment is performed at different input power and the corresponding output power of transmitted beam is noted and a graph is drawn between input power and output power for different dye 
concentrations and is shown in figure 13.

In this case of DO-25 dye sample with defocusing nonlinearity (negative nonlinearity), the intensity of transmitted beam at output is observed to change linearly at low values of the input intensity, but appears to saturate after a certain threshold value due to the fact that the dye sample starts defocusing the transmitting beam, resulting blocking of the part of the beam by the aperture A placed in between the dye sample and the collecting lens before the photo-detector. Thus the light intensity received by the photo detector remained almost constant showing a saturation region as shown in figure 13.

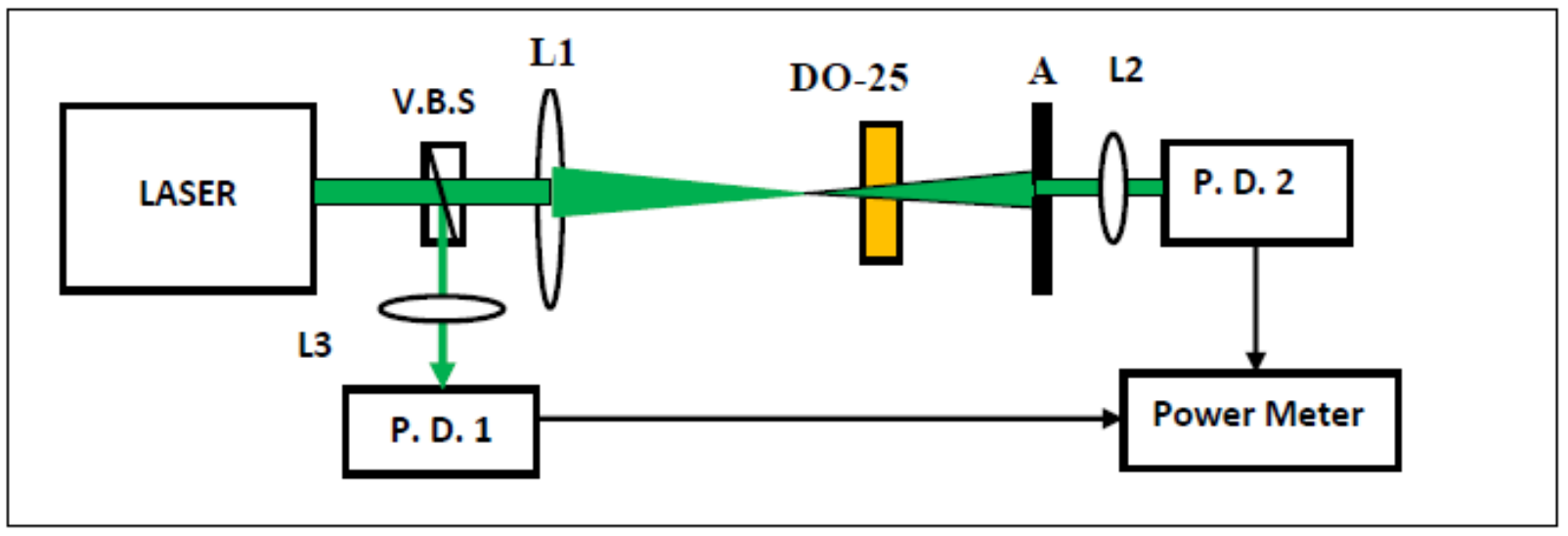

Figure 12: Experimental setup for closed aperture Optical limiting for DO-25 doped PMMA-MA using nonlinear refraction.

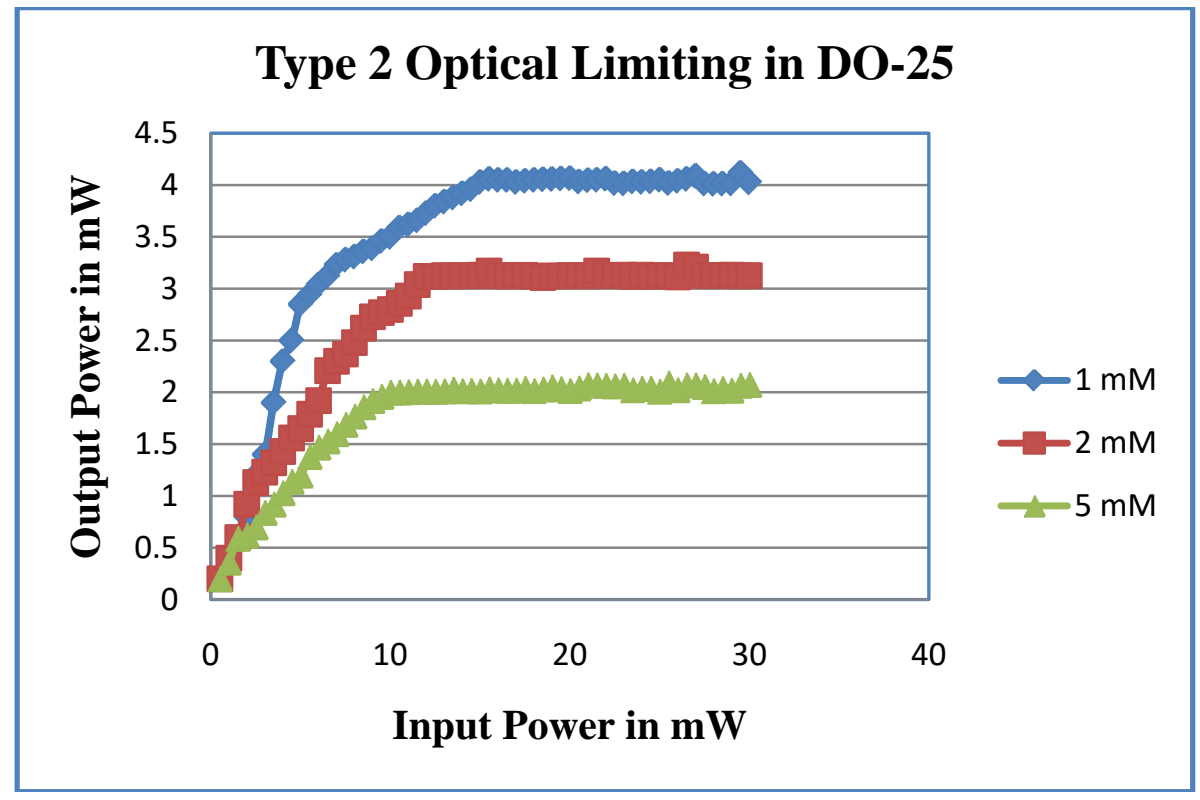

Figure 13: Closed aperture (Type 2) Optical limiting behavior of DO-25 dye-doped PMMA-MA film at CW $532 \mathrm{~nm}$.

\section{RESULTS \& DISCUSSION :}

In this section, we have studied the nonlinear optical properties of organic dye material DO-25 in PMMA-MA polymer matrix for their nonlinear absorption using open aperture Z-scan, nonlinear refraction using closed aperture Z-scan, and for optical limiting using type 1 and type 2 optical limiting configurations. Based on our study we observed that the nature of nonlinearity shown by DO25 dyes depends on the intensity of input laser light beam. At the lower intensity of input beam, the saturation absorption became prominent and with an increase in input intensity further, the excited state absorption in the form of reverse saturation absorption or thermally induced absorption became 
prominent.

It is also observed from other studies [29-39] that the value of $\Delta \mathrm{T}_{\mathrm{p}-\mathrm{v}}$ has increased in the case of dyedoped polymer films when compared to the dyes in the solvent. This shows that the change in refractive index due to reverse saturation absorption as well as thermal effect in solid media is larger compared to that of the liquid media. The heat dissipation rate in the liquid is more than that in the film because of the poor thermal conductivity of the polymer film. This leads to increase in temperature in solid media compared to temperature rise in liquid media which might increase nonlinear absorption. So, the nonlinear refractive index change is more in solid media than in liquid media.

In this study, it is observed that the value of the nonlinear refractive index and nonlinear absorption coefficient of DO-25 dye-doped polymer films depends on the concentration of the dyes in the polymer film. It is seen that there is an increasing trend in values of $n_{2}, \beta$, and $\left|\chi^{(3)}\right|$ as the concentration increases. This may be explained by the fact that the number of dye molecules increases when the concentration increases, more dye molecules get involved in the nonlinear process (twophoton absorption/reverse saturation) due to thermal agitation resulting in an enhanced effect. Thus Zscan measurements indicate that these dyes exhibit large nonlinear optical properties.

Table 6: Nature of Nonlinearity of DO-25 dye samples doped in PMMA-MA polymer films.

\begin{tabular}{|l|l|l|l|}
\hline S. No. & Dye & Medium & Nature of Nonlinearity \\
\hline 1 & Disperse Orange DO-25 & $\begin{array}{l}\text { PMMA-MA polymer } \\
\text { film }\end{array}$ & $\begin{array}{l}\text { Negative Nonlinearity } \\
\text { Defocusing effect }\end{array}$ \\
\hline
\end{tabular}

Table 7: Nonlinear parameters for dye-doped samples at $532 \mathrm{~nm}$.

\begin{tabular}{|c|c|c|c|}
\hline S. No. & Parameter & Dye concentration & DO-25 \\
\hline \multirow[t]{3}{*}{1} & \multirow{3}{*}{$\begin{array}{l}\beta \\
\left(\times 10^{-3}\right) \\
(\mathrm{cm} / \mathrm{W})\end{array}$} & $1 \mathrm{mM}$ & -0.74 \\
\hline & & $2 \mathrm{mM}$ & -0.88 \\
\hline & & $5 \mathrm{mM}$ & -1.13 \\
\hline \multirow[t]{3}{*}{2} & \multirow{3}{*}{$\begin{array}{l}\mathrm{n}_{2} \\
\left(\times 10^{-7}\right)\left(\mathrm{cm}^{2} / \mathrm{W}\right)\end{array}$} & $1 \mathrm{mM}$ & -0.325 \\
\hline & & $2 \mathrm{mM}$ & -0.557 \\
\hline & & $5 \mathrm{mM}$ & -0.836 \\
\hline \multirow[t]{3}{*}{3} & \multirow{3}{*}{$\begin{array}{l}\Delta \mathrm{n}=\mathrm{n}_{2} \mathrm{I}_{0} \\
\left(\times 10^{-4}\right)\end{array}$} & $1 \mathrm{mM}$ & -1.138 \\
\hline & & $2 \mathrm{mM}$ & -1.950 \\
\hline & & $5 \mathrm{mM}$ & -2.926 \\
\hline \multirow[t]{3}{*}{8} & \multirow[t]{3}{*}{$\left|\chi^{3}\right|\left(\times 10^{-6}\right)$ (e.s.u. $)$} & $1 \mathrm{mM}$ & 5.69 \\
\hline & & $2 \mathrm{mM}$ & 7.45 \\
\hline & & $5 \mathrm{mM}$ & 9.73 \\
\hline
\end{tabular}

The mechanism responsible for type 1 optical limiting is mainly attributed to reverse saturation absorption in case of DO-25, which further increased with thermally induced nonlinearity. The defocusing effect observed in DO-25 dye-doped samples under CW illumination is utilized to demonstrate type 2 optical limiting action. Based on their nonlinear refractive index, these dyes in PMMA-MA matrix behave as good optical limiters even at low powers. These results are quite impressive and encouraging for possible applications in nonlinear optical devices.

Table 8 lists details on various optical limiting regions in DO-25 dye-doped Polymer films at $532 \mathrm{~nm}$ $\mathrm{CW}$ laser beam. It is found that both type 1 and type 2 optical limiting effects show an increase in limiting action with increasing the concentration of the DO-25 dye in the polymer film. The optical limiting responses of the low dye concentration films are generally much weaker than those of high dye concentrated films. This shows that the number density of dye molecules in the polymer matrix along the path of the laser beam is the deciding factor to fix output clamping level.

Table 8: Optical limiting Regions in Dye-doped Polymer films at $532 \mathrm{~nm}$ CW laser beam.

\begin{tabular}{|l|l|l|l|l|l|}
\hline $\begin{array}{l}\text { S. } \\
\text { No. }\end{array}$ & Sample & $\begin{array}{l}\text { Dye } \\
\text { Concentration }\end{array}$ & $\begin{array}{l}\text { Linear Region } \\
\text { (mW) }\end{array}$ & $\begin{array}{l}\text { Active Region } \\
\text { (mW) }\end{array}$ & $\begin{array}{l}\text { Saturation } \\
\text { Region (mW) }\end{array}$ \\
\hline 1 & DO-25 in & $1 \mathrm{mM}$ & $1-5 \mathrm{~mW}$ & $5-22 \mathrm{~mW}$ & $22 \mathrm{~mW}$ onwards \\
\cline { 3 - 6 } & PMMA-MA & $2 \mathrm{mM}$ & $1-8 \mathrm{~mW}$ & $8-25 \mathrm{~mW}$ & $25 \mathrm{~mW}$ onwards \\
\hline
\end{tabular}

Shubrajyotsna Aithal et al, (2017); www.srinivaspublication.com $\quad$ PAGE 30 


\begin{tabular}{|l|l|l|l|l|l|}
\hline & Type 1 & $5 \mathrm{mM}$ & $1-10 \mathrm{~mW}$ & $10-27 \mathrm{~mW}$ & $27 \mathrm{~mW}$ onwards \\
\hline 2 & $\begin{array}{l}\text { DO-25 in } \\
\text { PMMA-MA }\end{array}$ & $1 \mathrm{mM}$ & $1-5 \mathrm{~mW}$ & $4-14 \mathrm{~mW}$ & $\begin{array}{l}14 \mathrm{~mW} \\
\text { onwards }\end{array}$ \\
\cline { 3 - 6 } & \multirow{2}{*}{ Type 2 } & $2 \mathrm{mM}$ & $1-8 \mathrm{~mW}$ & $8-11 \mathrm{~mW}$ & $\begin{array}{l}11 \mathrm{~mW} \\
\text { onwards }\end{array}$ \\
\cline { 3 - 6 } & $5 \mathrm{mM}$ & $1-7 \mathrm{~mW}$ & $7-9 \mathrm{~mW}$ & $\begin{array}{l}9 \mathrm{~mW} \\
\text { onwards }\end{array}$ \\
\hline
\end{tabular}

From Table 9, it can be seen that the optical power limiting threshold is inversely proportional to the dye concentration in the film. The limiting experiment shows that as the concentration increases, a reduction in linear transmittance as well as the output clamping level. The experimentally determined optical limiting saturated output power values at different dye concentrations are shown in Table 10. The results are comparable to some of the reports of low power optical limiting [40-55].

In the case of type 2 optical limiter with aperture, as observed in our experiment and in other published results, it is seen that at the valley positions, the limiter works at low input powers as the self-focusing/self-defocusing effect is increased by the thermal effect due to the absorptive properties of the dye used in polymer matrix. Thus it can be suggested that the best position for a dye sample, when used for optical limiting based on Type 2 self-focusing/self-defocusing position is at the valley point of the Z-scan curve.

Table 9: Concentration dependence of limiting Input threshold of DO-25 dye-doped in PMMA-MA films.

\begin{tabular}{|c|c|c|c|c|}
\hline S. No. & Sample & $\begin{array}{l}\text { Dye } \\
\text { Concentration } \\
\text { (mM) }\end{array}$ & $\begin{array}{l}\text { Type 1 Optical } \\
\text { Limiting } \\
\text { Threshold (mW) }\end{array}$ & $\begin{array}{l}\text { Type 2 Optical } \\
\text { Limiting Input } \\
\text { Threshold (mW) }\end{array}$ \\
\hline \multirow[t]{5}{*}{1} & \multirow{5}{*}{$\begin{array}{ll}\text { DO-25 in } \\
\text { PMMA-MA }\end{array}$} & $1 \mathrm{mM}$ & 22 & 15 \\
\hline & & $2 \mathrm{mM}$ & 25 & 12 \\
\hline & & $5 \mathrm{mM}$ & 27 & 10 \\
\hline & & $2 \mathrm{mM}$ & 25 & 17 \\
\hline & & $5 \mathrm{mM}$ & 26 & 09 \\
\hline
\end{tabular}

Table 10: Concentration dependence of saturated output power in DO-25 dye-doped PMMA-MA films.

\begin{tabular}{|c|c|c|c|c|}
\hline S. No. & Sample & $\begin{array}{l}\text { Dye } \\
\text { Concentration } \\
\text { (mM) }\end{array}$ & $\begin{array}{lr}\text { Type } 1 & \text { Optical } \\
\text { Limiting } & \text { Saturated } \\
\text { Output Power }(\mathrm{mW})\end{array}$ & $\begin{array}{lr}\text { Type } 2 & \text { Optical } \\
\text { Limiting } & \text { Saturated } \\
\text { Output Power }(\mathrm{mW})\end{array}$ \\
\hline \multirow[t]{3}{*}{1} & \multirow{3}{*}{$\begin{array}{l}\text { DO-25 in } \\
\text { PMMA-MA }\end{array}$} & $1 \mathrm{mM}$ & 5.10 & 4.0 \\
\hline & & $2 \mathrm{mM}$ & 4.0 & 3.10 \\
\hline & & $5 \mathrm{mM}$ & 2.92 & 1.99 \\
\hline
\end{tabular}

\section{CONCLUSION :}

The nonlinear absorption, nonlinear refraction properties of DO-25 dye-doped in Polymethyl methacrylate methacrylic acid (PMMA-MA) polymer film are studied at low power CW laser beam of $532 \mathrm{~nm}$ using the Z-scan experimental method. The optical limiting properties of these films are also studied by increasing input power at different dye doping concentrations. It is found that the type of nonlinear absorption depends on the intensity of input beam. DO-25 has shown saturation absorption at lower input irradiance and reverse saturation absorption at higher irradiance. Optical limiting studies using type 1 and type 2 setups is carried out and is found that type 2 has shown better limiting characteristics for DO-25 doped PMMA-MA polymer films. Hence DO-25 dye-doped in PMMA-MA polymer film can be a potential candidate for the third harmonic property based photonic devices. 


\section{REFERENCES :}

[1] Bredas, J. L. Adant, C. Tackx, P. Persoons, A. Pierce, B. M.(1994). 3rd-Order Nonlinear-Optical Response in Organic Materials - Theoretical and Experimental Aspects. Chemical Reviews, 94, 243.

[2] Perry, J. W. in Nonlinear Optics of Organic Molecules and Polymers, eds. H. S. Nalwa and S. Miyata, ( CRC Press, Boca Raton, Fla., 1997), Chap. 13, pp.813-840.

[3] Said, A. A, Wamsely, C., Hagan, D. J., Van Stryland, E. W., B. A. Reinhardt, B. A., Roderer, P., \& Dillard, A. G. (1994). Third-and fifth-order optical nonlinearities in organic materials. Chem. Phys. Lett. 228, 646.

[4] Gunter, P., Huignard, J. P. (1989). Photorefractive Materials and Their Applications I \&II, Topic in Applied Physics, Vol. 61, Springer-Verlag, Berlin, 1988.

[5] Manjunatha, K. B., Dileep, R., Umesh, G., \& Bhat, B. R. (2013). Nonlinear optical and all-optical switching studies of novel ruthenium complex. Optics \& Laser Technology, 52, 103-108.

[6] Jaffar, A. F. (2013). Solvent effect on the third order nonlinearity of oxazine dye doped PMMA films by using Z-scan techniques. Int. J. Adv. Res. Technol, 2(11), 56-64.

[7] Kumar, G.R., Singh, B. P., \& Sharma, K. K. (1989). Optical phase conjugation in Rhodamine-6G doped boric acid glass, Optics Communications, 73, 81-84.

[8] Zainab S. Sadik, Dhia H. Al-Amiedy, Amal F. Jaffar, Third Order Optical Nonlinearities of C450 Doped Polymer Thin Film Investigated by the Z-Scan, Advances in Materials Physics and Chemistry, 2, (2012), pp 43-49

[9] Prasad, L. G. (2014). Azo dye doped polymer films for nonlinear optical applications. Chinese Journal of Polymer Science, 32(5), 650-657.

[10] Pramodini, S., \& Poornesh, P. (2014). Third-order nonlinear optical response of indigo carmine under 633nm excitation for nonlinear optical applications. Optics \& Laser Technology, 63, 114119.

[11] Yee, K.C. Tou, T.Y. and Ng, S. W. (1998). Hot-press molded PMMA matrix for solid-state dye lasers, Applied Optics, 37, 6381-6385.

[12] O.Chen, Quian.Y, Chen Z \& Y. Zang, T., (1995). Fabrication of ultrafine SnO2 thin films by the hydrothermal method, Thin Solid Films, 264, 25-27.

[13] Badran, H. A. Mohammed, F. Al-Mudhaffer, Q. M. A. Hassan, A. Y. Al-Ahmad, (2012). Study of the linear optical properties and surface energy loss of 5', 5"-dibromo-o-cresolsulfophthalein thin films, Chalcogenide Letters., 9(12), 483 - 493.

[14] Jedrzejewska, B., Gordel, M., Szeremeta, J., Krawczyk, P., \& Samoć, M. (2015). Synthesis and Linear and Nonlinear Optical Properties of Three Push-Pull Oxazol-5 (4 H)-one Compounds. The Journal of organic chemistry, 80(19), 9641-9651.

[15] Hales, J. M., Barlow, S., Kim, H., Mukhopadhyay, S., Brédas, J. L., Perry, J. W., \& Marder, S. R. (2013). Design of organic chromophores for all-optical signal processing applications. Chemistry of Materials, 26(1), 549-560.

[16] Arabath Ali, A.S., Sindhu, V., Srinivasan, A. G. (2015). Nonlinear optical studies of bromothymol blue in liquid and solid media. Optik - International Journal for Light and Electron Optics, 126(9-10), 962-966.

[17] Nasseri, F., Rokhsat, E., Dorranian, D. (2016). Low power continues wave nonlinear optics in red BS dye doped PVA thin film. Optik - International Journal for Light and Electron Optics, 127(17), 6813-6820. 
[18] Sheik-Bahae, M., Said, A. A. \& Van Strayland, E. W. (1989). High Sensitivity Single beam n2 Measurement. Opt. Lett., 14, 955-957.

[19] Sheik-Bahae, M., Said, A. A., Wei, T., Hagan, D. J. and Van Strayland, E.W. (1990). Sensitivitive measurement of optical nonlinearities using a single beam. IEEE J. Quantum Electron., 26, 760-769.

[20] Sheik-Bahae, M., Said, A. A., Hagan, D. J., Soileau, M. J., \& Van Stryland, E. W. (1991). Nonlinear refraction and optical limiting in thick media. Opt. Eng, 30(8), 1228-1235.

[21] Van Stryland, E. W., \& Sheik-Bahae, M. (1998). Z-scan measurements of optical nonlinearities. Characterization techniques and tabulations for organic nonlinear materials, 18(3), 655-692.

[22] Mansour, K., Soileau, M. J. and Van Stryland, E. W. (1992). Nonlinear optical properties of carbon-black suspensions (ink). J. Opt. Soc.Am. B9, 1100.

[23] Williams, W.E. Soileau, M.J. and Van Stryland, E.W. (1984). Optical Switching and $\mathrm{n}_{2}$ Measurements in $\mathrm{CS}_{2}$, Opt. Comm., 50, 256-260.

[24] Cassano T, Tommasi R, Ferrara M, Babudri F, Farinola GM and Naso F (2001). Substituent dependence of the optical nonlinearities in poly (2,5-dialkoxy-pphenylenevinylene) polymers investigated by the Z-scan technique. Chem. Phys. 272, 111-118. DOI:10.1016/S03010104(01)00453-0.

[25] Rekha, R. K. \& Ramalingam, A. (2009). Non-linear characterization and optical limiting effect of carmine dye. Indian Journal of Science and Technology, 2(8), 27-31.

[26] Aithal, P. S., Ravindra Prathap Singh, \& Narayana Rao (2003). Optical limiting due to frequency up-converted fluorescence in DASPB dye doped polymer matrix. Proceedings of SPIE, 4797, 229-239.

[27] Ravindra Pratap Singh, S. Aithal and Narayana Rao (2003). Optical limiting studies of Disperse Orange and Disperse Yellow in PMMA-MA matrix. Proc. of SPIE, 4797, 52-58.

[28] Wang, C, Ren, Y., Shao, Z., Zhao, X., Zhou, G., Wang, D., Fang, Q and Jiang, M. (2001). Optical properties of New two photon absorbing material HMASPS, Nonlinear Optics, 28, 1-13.

[29] Sathy P., Philip R., Nampoori V. P. N., and Vallabhan C. P. G., (1994). Photoacoustic observation of excited state absorption in the laser dye Rhodamine 6G, J. Phys. D 27, 20192022.

[30] Pramodin, S., Poornesh, P., Nagaraja, K. K. (2013). Thermally induced nonlinear optical response and optical power limiting of acid blue 40 dye. Current Applied Physics, 13(7), 1751182.

[31] Manshad, R. K. and Hassan, Q. M. A. ( 2012 ). Nonlinear characterization of Orcein solution and dye doped polymer film for application in optical limiting. Journal of Basrah Researches ((Sciences)), 38(4), 125-133.

[32] Rekha, R.K. and Ramalingam, A. (2009). Optical Nonlinear Properties and Optical Limiting Effect of Metanil Yellow, American J. of Engineering and Applied Sciences 2 (2): 285-291.

[33] Rajashekar, B. Sagar Limbu, Kamarusu Aditya, Nageswara Rao, G. \& Siva Sankara Sai, S. (2013). Azo doped polymer thin films for active and passive optical power limiting applications. Photochem. Photobiol. Sci., 12(10), 1780-1786.

[34] Nagaraja, K.K., Pramodini, S., Santhosh Kumar, A. Nagaraja, H. S., Poornesh, P. \& Dhananjaya Kekuda. (2013). Third-order nonlinear optical properties of Mn doped ZnO thin films under CW laser illumination. Optical Materials. 35(3), 431-439. 
[35] Pradeep, C., Mathew, S., Nithyaja, B., Radhakrishnan, P. and Nampoori, V.P.N., (2014). Studies of nonlinear optical properties of PicoGreen dye using Z-scan technique, Applied Physics A, 115, 291-295.

[36] Shubrajyotsna Aithal, Aithal, P. S. \& Bhat, G. K. (2011). Optical Nonlinearity of Dye-doped Polymer Film using Z-scan Technique. Proceedings of Second International Conference on Photonics, Kota Kinabalu, Malaysia, IEEEXplore, ISBN 978-1-61284-265-3, pp 62-66. DOI: 10.1109/ICP.2011.6106884.

[37] Shubrajyotsna Aithal, Aithal, P. S. \& Bhat, G. K. (2011). Study of nonlinear absorption in a dye doped polymer film due to frequency up-converted fluorescence. Proceedings of the International Conference on Laser, Material Science and Communication, Ed. Chatterjee, U. \& Chakrabarti, P. K. ISBN : 978-93-80813-14-1, pp. 107-109, (2011), DOI : 10.5281/zenodo.62033.

[38] Shubrajyotsna Aithal, Aithal, P. S. \& Bhat, G. K. (2012). Phase Conjugation in Two Photon Absorbing Dye films by Degenerate Four-wave Mixing, $3^{\text {rd }}$ International Conference on Photonics 2012, Malaysia. IEEEXplore ISBN: 978-1-4673-1463-3, pp - 235-239. DOI : 10.1109/ICP.2012.6379868.

[39] Shubrajyotsna Aithal, Aithal, P. S. \& Bhat, G. K. (2015). A Review On Sustainable Organic Materials for Optical Limiting Technology. International Journal of Management, IT and Engineering (IJMIE), 5(7), 527-544. DOI : 10.5281/zenodo.62032.

[40] Shubhrajyotsna Aithal, \& Aithal P. S., (2016). ABCD analysis of Dye doped Polymers for Photonic Applications, IRA-International Journal of Applied Sciences, 4(3), 358-378. DOI : http://dx.doi.org/10.21013/jas.v4.n3.p1.

[41] Kaladevi, S. Vijayan, C. Kothiyal, M.P. (2004). Opt. Mater. 27, 1606.

[42] Balaji, G. Rekha R. K. \& Ramalingam, A. (2011). Nonlinear Characterization of Safranin O Dye for Application in Optical Limiting. ACTA PHYSICA POLONICA A, 119(3), 359-363.

[43] Shubrajyotsna Aithal, Aithal, P. S. and Bhat, G. K. (2016). CW Optical Limiting Study in Disperse Yellow Dye-doped PMMA-MA Polymer Films. IRA-International Journal of Applied Sciences, 5(3), 129-146. DOI: http://dx.doi.org/10.21013/jas.v5.n3.p4.

[44] Shubrajyotsna Aithal, Aithal, P. S. \& Bhat, G. K. (2016). Type 1 \& Type 2 Optical Limiting Studies in Disperse Orange-25 Dye-doped PMMA-MA Polymer Films using CW Laser. International Journal of Applied and Advanced Scientific Research (IJAASR), 1(1), 196-208. DOI : http://doi.org/10.5281/zenodo.208184.

[45] Shubrajyotsna Aithal, \& Aithal, P. S., Bhat, G. K. (2016). Characteristics of Ideal Optical Limiter and Realization Scenarios using Nonlinear Organic Materials - A Review. International Journal of Advanced Trends in Engineering and Technology (IJATET), 1(1), 73-84. DOI : http://doi.org/10.5281/zenodo.240254.

[46] Singh, R. P., Aithal, P. S. \& Rao, D. N. (2003). Optical limiting studies of Disperse Orange and Disperse Yellow in PMMA-MA matrix. Proc. of SPIE, 4797, 52-58.

[47] Aithal, P. S., Kiran, P. P., Rao, D. N. (2000). Optical limiting studies in photorefractive pure and iron-doped $\mathrm{Bi}_{12} \mathrm{SiO}_{20}$ crystals. - Journal of Nonlinear Optical Physics \& Materials, 9(2), 217-225.

[48] Aithal, P. S., Singh, R. P. \& Rao, D. N. (2003). Optical limiting due to frequency up-converted fluorescence in DASPB dye doped polymer matrix. Proceedings of SPIE, 4797, 229-239.

[49] Shubhrajyotsna Aithal, Aithal, P. S. \& Bhat, G. K. (2013). Study of Optical Limiting and Optical Phase Conjugation in DASPB dye-doped polymer films, GSTF Journal of Physics and Applications (JPA), 1(1), 15-24. DOI: 10.5176/2335-6901.1.1.3. 
[50] Shubrajyotsna Aithal, Aithal, P. S. \& Bhat, G. K. (2013). Degenerate four-wave mixing in DASPB dye-doped polymer film, published in Part IV Quantum Optics, Chapter 12, Advances in Laser Physics and Technology, Edited by Man Mohan, Anil Kumar Maini, Aranya A. Bhattacherjee and Anil K. Razdan under the imprint of Foundation Books, Cambridge University Press India Pvt Ltd., pp. 179 - 195, ISBN: 978-93-844634-1-0., DOI : 10.5281/zenodo.62048.

[51] Shubrajyotsna Aithal, Aithal, P. S. \& Bhat, G. K. (2012). Phase Conjugation in Two Photon Absorbing Dye films by Degenerate Four-wave Mixing, $3^{\text {rd }}$ International Conference on Photonics 2012, 1-3 October 2012, Penang, Malaysia. Published in IEEEXplore ISBN: 978-14673-1463-3, pp.235-239.

[52] Shubrajyotsna Aithal, Aithal, P. S. (2012). Study of Phase Conjugated wave in DASPB dyedoped polymer films, Photonics Global Conference 2012, 13-16, December 2012, Nanyang Technical University, Singapore. In Photonics Global Conference (PGC), Singapore, pp.1-5. IEEE. ISBN : 978-1-4673-2513-4, DOI:10.1109/PGC.2012.6458057.

[53] Shubrajyotsna Aithal, Aithal, P. S. and Bhat, G. K. (2016). Study of Low Power Degenerate Four-Wave Mixing in Disperse Yellow Dye-doped Polymer Film. International Journal of Engineering Research and Modern Education (IJERME), 1(2), 200-209. DOI: http://dx.doi.org/10.5281/ZENODO.198716.

[54] Shubrajyotsna Aithal, Aithal, P. S. \& Bhat, G. K. (2017). Study of Third Order Optical Nonlinearity in DASPB Dye-doped Polymer Films using CW Laser. Saudi Journal of Engineering and Technology (SJEAT), 2(1), 32-48. DOI : http://doi.org/10.21276/sjeat.2017.2.1.4.

[55] Shubrajyotsna Aithal, \& Aithal P. S. (2017). Research Opportunities for Use of Organic Dyes \& Dye-doped Polymers in Optoelectronics and Photonics. International Journal of Engineering Research and Modern Education (IJERME).2(1), 90-97. DOI : http://doi.org/10.5281/zenodo.546772. 